\title{
LA TEORIA DEL CAPITAL HUMANO: UNA CONTRASTACION EMPIRICA. LA ESPAÑA INDUSTRIAL EN EL SIGLO XIX ${ }^{1}$
}

\author{
ENRIQUETA CAMPS CURA \\ Instituto Universitario Europeo
}

1. El mercado de trabajo.

Las teorias del capital bumano y de los mercados internos

Si nos basamos en los manuales de teoría neoclásica tradicionales, en un sistema de mercado, el trabajo es un factor de producción de características similares a los demás productos. El libre juego de oferta y demanda lleva a un salario de equilibrio que depende de la tecnología utilizada, único factor exógeno al mercado de trabajo, que influye en la productividad y, por tanto, en la determinación del salario. La teoría neoclásica, no obstante, se ha sofisticado con la teoría de la formación de capital humano de G. S. Becker ${ }^{2}$. La idea principal de esta teoría intenta explicar las diferencias salariales dentro del mercado de trabajo. Estas diferencias, siguiendo al mismo autor, obedecen a los niveles distintos de cualificación con que los trabajadores se incorporan al mercado de trabajo, niveles de cualificación que dependen, sobre todo, del tiempo invertido para adquirirlos. Las personas cualificadas renunciaron en su momento a la renta inmediata que les ofrecía el mercado de trabajo, en aras de un mayor ingreso futuro. El equilibrio se alcanza cuando los ingresos futuros compensan los sacrificios presentes. Cuando la formación es general, es decir, aplicable a cualquier empresa, el propio trabajador paga los costes de formación. Cuando la formación es específica, sólo útil para una empresa, los costes de formación son compartidos entre el trabajador y la empresa, de forma que la parte pagada por la empresa no tiene ninguna incidencia en la curva de ingresos futuros del trabajador. En los casos en que la

1 Una primera versión de este artículo fue presentada como ponencia en el IV Congreso de la Asociación de Historia Económica. Agradezco todos los comentarios recibidos, que espero me hayan permitido perfeccionar esta nueva versión del trabajo, aunque, lógicamente, la responsabilidad de los posibles errores sea sólo mía. Las deudas contraídas en la confección de la primera versión del trabajo fueron numerosas. Quiero, no obstante, destacar la ayuda de Anna M. Aubanell, Albert Carreras, Jordi Catalán, Jordi Maluquer, Jordi Nadal, Albert Recio, Jordi Roca, Jaume Torras y Stuart Woolf.

'Becker (1964). 
empresa invierte en los trabajadores, ésta estará poco interesada en sustituirlos, de forma que disminuye la rotación del trabajo. Según G. S. Becker, se ha comprobado que las empresas se benefician más de la inversión en capital humano, cuanto más específico sea su efecto sobre la productividad, cuanto mayor sea su poder monopsonista y cuanto más largo sea el contrato de trabajo.

La teoría de la formación de capital humano para explicar las diferencias salariales ha sido puesta en tela de juicio por los economistas que han acotado los conceptos de mercados internos de trabajo y mercado dual de trabajo. En esta dirección, las aportaciones de Piore y Doeringer son las pioneras ${ }^{3}$. La crítica a la teoría del capital humano que hacen estos autores no es meramente metodológica. De hecho, pone en duda la hipótesis individualista de la conducta de los trabajadores, según la cual un individuo es capaz de distinguir entre medios y fines independientemente de la conducta de los demás individuos. Según los autores citados, la conducta dominante en el mercado de trabajo es la consuetudinaria. Ponen, en definitiva, de relieve, las interdependencias de las funciones de utilidad de los individuos en el mercado de trabajo. Según esta corriente de análisis económico, el mercado de trabajo no es susceptible de ser analizado como cualquier otro mercado, ya que la hipótesis de la independencia de las funciones de utilidad no es válida. A la luz de las evidencias más recientes, estos autores ponen de relieve cómo los trabajadores pasan muy brevemente por el mercado de trabajo y, en cambio, pasan la mayor parte de sus vidas dentro de una única empresa ${ }^{4}$. La formación en el trabajo parece que, en sus características esenciales, obedece a un proceso de socialización. Una parte importante de la productividad del trabajador se puede atribuir a la forma como se relaciona con sus colegas y con los grupos sociales que éstos forman. Así, pues, el proceso de ajuste a un nuevo trabajo es un proceso en que el individuo se adapta al grupo de trabajo y aprende sus normas y costumbres.

La teoría de los mercados internos, normalmente se asocia a tres elementos institucionales distintos, pero interdependientes. En primer lugar, la asignación de trabajo se lleva a cabo dentro de la empresa, a través de la promoción de los trabajadores en lo que se ha venido llamando escaleras ocupacionales (job ladders). El tipo ideal de un tal funcionamiento del mercado consiste en un conjunto de normas que limita los contratos de nuevos trabajadores a ciertas ocupaciones o puertos de entrada, habitualmente en la base de la jerarquía salarial de la empresa, mientras que se reserva el resto de puestos de trabajo a los trabajadores ya empleados en la empresa ${ }^{5}$.

'Doeringer y Piore (1985) y (1983), pp. 341-388.

Doeringer y Piore (1985); Osterman (1984). 
Estos últimos puestos de trabajo están protegidos de la influencia de las fuerzas competitivas del mercado de trabajo. Se ordenan, además, en grados de antigüedad o líneas de progresión, de forma que las vacantes se cubren mediante la promición de los trabajadores situados en la clasificación inmediatamente inferior en la línea de progresión.

En segundo lugar, algunos sectores de trabajadores gozan de una considerable seguridad de empleo, con contratos de trabajo a largo plazo. Un am. plio porcentaje de trabajadores adquiere de hecho relaciones contractuales con una misma empresa para toda la vida.

En tercer lugar, las relaciones contractuales están gobernadas por normas burocráticas e impersonales, asi como por la supervisión de los managers. Las decisiones sobre tarifas salariales y condiciones de trabajo no se dejan en manos de los capataces, sino que están determinadas por normas centralizadas $y$, en muchos casos. por la negociación entre empresas y sindicatos". No obstante, tal como se ha señalado, la empresa tiene un amplio grado de autonomía en la asignación del trabajo y la confección de escaleras ocupacionales. Tal como señala P. Osterman, el reclutamiento interno de los puestos de trabajo medios y altos del abanico salarial y el peso de la antigüedad en la fijación del salario, hacen que la distribución de las posiciones de ocupación y los ingresos estén en gran medida disociados de las características del capital humano de los individuos involucrados. Además, la distribución de los ingresos a !o largo de la vida puede variar de una empresa a otra, de forma que un análisis cross-section de la jerarquía salarial difícilmente puede llevar a resultados fiables ${ }^{7}$. Estos aspectos de la reoría de los mercados internos distancian de nuevo el marco de análisis del utilizado por la teoría de la formación de capital humano. Aunque esta última pone énfasis en la importancia para la empresa de la formación específica y los contratos de larga duración, señala también cómo el sistema de salarios es único y está determinado por los costes relativos y productividades marginales, y no por leyes consuetudinarias y prácticas de socialización que hacen variar los mecanismos de determinación de los salarios de una a otra empresa.

El segundo concepto acotado por Doeringer y Piore es el de estratificación o dualidad del mercado de trabajo. Según estos autores, podemos dividir, a grandes rasgos, el mercado de trabajo en dos sectores: un sector primario $y$ un sector secundario. El sector primario se refiere a aquellas ocupaciones que ofrecen salarios elevados, oportunidades de ascenso social, equidad, estabilidad y procedimientos establecidos en cuanto a la aplicación de normas

'Doeringer y Piore (1985), cap. 3.

- Sundstrom (1988).

Osterman (1984). Con ello, el autor pone en rela de juicio la metodología urilizada por J. G. Williamson para medir las desigualdades salariales. Véase J. G. Williamson (1987). 
laborales. En cambio, los trabajadores del sector secundario comprenden aquellos segmentos del trabajo peor pagados, con pocas posibilidades de promoción, una relación muy personalizada entre trabajador y supervisor, inestabilidad y un alto grado de rotación de la población trabajadora. A veces se identifican con grupos raciales o de sexo, que no tienen las mismas oportunidades de acceso a ocupaciones bien retribuidas que los otros segmentos de la población ${ }^{8}$. ¿Cómo afecta la segmentación o dualidad del mercado de trabajo a las cadenas de movilidad o escaleras ocupacionales a que antes se ha aludido? Según Piore, en el sector secundario hay pocas oportunidades de que estas cadenas de movilidad operen. Los puestos de trabajo ocupados por los trabajadores de este sector son aleatorios, manteniéndose una amplia rotación del trabajo y no secuencias de cualificación. Según el mismo autor, estas formas de movilidad aleatoria están enraizadas en familias, barrios y escuelas de las clases más bajas de la jerarquía social.

Aunque la tendencia dominante en la corriente económica que ha acotado y contrastado el concepto de mercados internos es la de asociar su surgimiento a la modernización industrial americana de la primera mitad del siglo $\mathrm{xx}$, la adopción de nuevas formas de gestión empresarial y la negociación entre empresarios y sindicatos ${ }^{9}$, las aportaciones más recientes muestran que su formación se remonta a la segunda mitad del siglo $\mathrm{xIX}^{10}$. En cambio, en el contexto europeo, aunque la historiografía ha utilizado formas de jerarquización del mercado de trabajo, siendo la más común la noción de aristocracia obrera ", no se ha usado ni contrastado el concepto de mercados internos.

Teniendo en cuenta los marcos analíticos y teóricos mencionados, se pondrá de relieve, a continuación, las características de la asignación del trabajo y la determinación del salario en la mayor empresa textil decimonónica de la península, la España Industrial.

\section{Metodologia y fuentes}

Las fuentes de información para el estudio de los salarios en Cataluña, abundantes para el siglo $\mathrm{xx}$, son escasas para el siglo $\mathrm{xIx}$, ya que se cuenta como única fuente con los archivos de empresa y éstos sólo raramente conservan series continuadas de salarios para el siglo pasado. No obstante, los datos disponibles han permitido ver cuál era el ingreso medio máximo a que un trabajador fabril podía aspirar a lo largo de su vida y reconstruir los sala-

- Piore (1983), pp. 193-222.

- Doeringer y Piore (1985); Gordon, Edwards y Reich (1986); Jacoby (1984).

10 Sundstrom (1988); Brown y Philips (1986).

" Hobsbawm (1964), cap. 15. 
rios según cohortes de matrimonios. Las fuentes utilizadas son las nóminas de la España Industrial y los expedientes de matrimonios que se conservan en el arzobispado de Barcelona.

Como es bien sabido, el enlace de informaciones a partir de la identificación de los individuos, es un proceso complejo y laborioso, no sólo por el trabajo que requiere, evidenciado en multitud de reconstituciones de familias. sino también por los problemas que surgen cuando se quiere identificar a un individuo en distintas fuentes documentales ${ }^{2}$. En nuestro caso, a la hora de decidir cómo identificar a los individuos, se ha utilizado los criterios especificados por Wrigley y Schofield ${ }^{13}$. En primer lugar, tener en cuenta todas las identificaciones posibles a partir del nombre. En segundo lugar, especificar el procedimiento de decisión cuando un individuo en una fuente tiene probabilidades de ser varios individuos en otra fuente. $Y$, en tercer lugar, que el procedimiento de decisión haga el mejor uso posible, no sólo de la información directamente implicada en la identificación, sino de toda la información ofrecida por los archivos que es relevante para la decisión.

Para la medida del ciclo vital se han utilizado, como se ha mencionado ya, las nóminas de la España Industrial en el período 1847-1887 y los expedientes matrimoniales de los años 1837-1867. Se ha tomado, como muestra, a todos los trabajadores que la fábrica reclutó en sus diez primeros años de existencia (1847-1857). Esta muestra representa un total de 1.098 hombres y 927 mujeres. Para cada uno de ellos se ha confeccionado una ficha en la que se ha ido registrando su salario a lo largo del tiempo. Después de un seguimiento individualizado año por año durante los diez primeros años, se ha registrado su salario cada cinco años durante un período de treinta años más (de 1857 a 1887). Con ello, para los trabajadores estables, se cuenta con la información de su salario a lo largo de un período de entre treinta y cuarenta años, que es lo que se puede considerar que duraba la vida activa en el siglo xix. No se conoce, en cambio, el destino de los trabajadores que dejan de aparecer en las nóminas de la empresa, ya sea porque han muerto, ya porque han sido despedidos o han dejado la fábrica. La medida de la evolución del salario a lo largo de la vida construida a partir de este método es, sin duda, un indicador máximo de lo que un trabajador podía ganar en períodos avanzados de su vida y no representa, necesariamente, a los trabajadores más inestables para los que sólo se dispone de información para períodos cortos de tiempo. No obstante, como se verá, el grado de estabilidad estaba también relacionado con el ciclo vital, de modo que es posible hacer hipótesis sobre la trayectoria de la ocupación y el salario a lo largo de la vida.

12 Para un proceso de identificación informatizado, véanse las aportaciones de Wrigley y Schofield (1973); Skolnik y otros (1977); Winchester (1985).

is Wrigley y Schofield (1973), p. 68. 
Debido a la inexistencia de cualquier copia de los manuscritos de los censos y padrones de Barcelona del siglo xix, los expedientes matrimoniales son el mejor indicador de la edad de los individuos. Relacionando los salarios con el matrimonio, se puede estimar la evolución del ingreso a lo largo del ciclo vital, ya que se puede considerar que los individuos celebraban las primeras nupcias a edades parecidas, alrededor de los veinticinco años ${ }^{14}$. A partir del número de años antes o después del matrimonio en que se cobraba un determinado salario, es posible reconstruir. longitudinalmente, la evolución del ingreso a lo largo del ciclo vital.

La identificación de los trabajadores de la España Industrial en los expedientes matrimoniales ha conllevado problemas que han reducido la muestra sensiblementc. En primer lugar, no se ha podido identificar a las mujeres, ya que éstas no se encuentran ordenadas alfabéticamente en el catálogo y es, por tanto, imposible establecer algún criterio de selección. Aunque la información de la empresa ha permitido reconstruir la evolución de su salario según la antigüedad, para ellas no se ha podido relacionar el ingreso con la edad.

En segundo lugar, la información que, adicionalmente al nombre y primer apellido, especifican las nóminas de la empresa es escasa. Se reduce a la fecha de entrada en la fábrica, que se ha conocido mediante el seguimiento individualizado año por año de los trabajadores; el lugar de residencia mientras trabajaban en la fábrica, ya que es de suponer que en este periodo vivían en Sants o en sus inmediaciones; y su ocupación precisa en la empresa. Así, como criterios de selección para la identificación de la población masculina de la fábrica se han utilizado los siguientes:

1. A partir de la estructura de edades de los inmigrantes y emigrantes de Sabadell, se puede deducir que la mayoria de los trabajadores entraban en una empresa a edades jóvenes, que no superaban los treinta y cinco años (Camps, 1990). Suponiendo que el primer matrimonio de los hombres se celebraba alrededor de los veinticinco años y que la entrada en la empresa, en la mayoría de los casos, se daba entre los quince y treinta y cinco años, se ha buscado a cada trabajador a lo largo de un total de veinte años, en el período comprendido entre los diez años anteriores y los diez años posteriores a su entrada en la empresa, registrando todos los matrimonios que con el nombre y apellido del trabajador se efectuaron en el arzobispado de Barcelona. Los nombres más comunes, para los que se ha encontrado 15 o más matrimonios, se han deses-

" Se ha tenido en cuenta esta cdad de matrimonio a partir de los resultados sobre nupcialidad obtenidos en Sabadell, yue sitúan la edad de matrimonio de los hombres en. tre los 24 y los 27 años a fo largo del siglo xix. Véase Camps (1985). Los resultados ob. tenidos en Sabadell, a 20 kilómetros de Barcelona, habrían de ser significativos de la nupcialidad de los trabajadores textiles, ya que éstos constituían cerca de la mitad de la población activa de la ciudad. 
timado, por la dificultad de establecer criterios de selección, mientras que la parte restante se ha buscado en los legajos correspondientes.

2." Si el matrimonio se celebraba en una fecha en que el trabajador estaba presente en la fábrica, se han elegido sólo aquellos casos en que el consorte residía en Sants o cerca de Sants en el momento de las primeras nupcias. Si el matrimonio se celebraba antes o después de la estancia en la fábrica y, dado el predominio de migraciones de corta distancia en la Cataluña del siglo xIX, se han escogido los individuos que residían más cerca de Sants, a no ser que la información sobre ocupación fuese incompatible - por ejemplo, el caso de un hacendado o rentista que tiene pocas probabilidades de convertirse en jornalero de fábrica-, o muy relevante - por ejemplo, se ha preferido un tejedor, residente en Tarrassa y nacido en Puigcerdà, a un carnicero que cuando se casó vivía en Cerdanyola-.

3." A partir de los datos sobre movilidad ocupacional a lo largo de la vida obtenidos en Tarrassa (Camps, 1990), se ha estimado poco probable que un trabajador cambiase de sector de ocupación a lo largo de su vida. La ocupación. tal tomo se ha mencionado en el punto anterior, permite desestimar algunos casos y, sobre todo cuando la estancia en la fábrica coincide con el matrimonio. permite identificar a los individuos.

El detalle de las ocupaciones seleccionadas para los individuos identificados se especifica en el cuadro 1. Así, el 71 por 100 de las observaciones corresponden a individuos que, cuando se casaron, eran trabajadores cualificados en el textil y un 15 por 100 jornaleros.

El 8 por 100 de los individuos ocupados en oficios tradicionales en el momento del matrimonio - artesanos- se explica porque la empresa tenía también secciones de carpintería, cerrajería y hojalatería, algunos de cuyos trabajadores se han encontrado con oficios similares en las primeras nupcias.

Como resultado de este proceso de identificación la muestra se ha reducido sensiblemente. De los 1.098 hombres que se han seguido en la fábrica, sólo se han seleccionado en los matrimonios 480 . El resto, o tenían nombres demasiado comunes 0 en las primeras nupcias tenían ocupaciones y lugares de residencia que se han considerado incompatibles con su trabajo en la fábrica de Sants, o no se han encontrado, por haberse casado fuera de la jurisdicción eclesiástica de Barcelona o fuera del período considerado. 


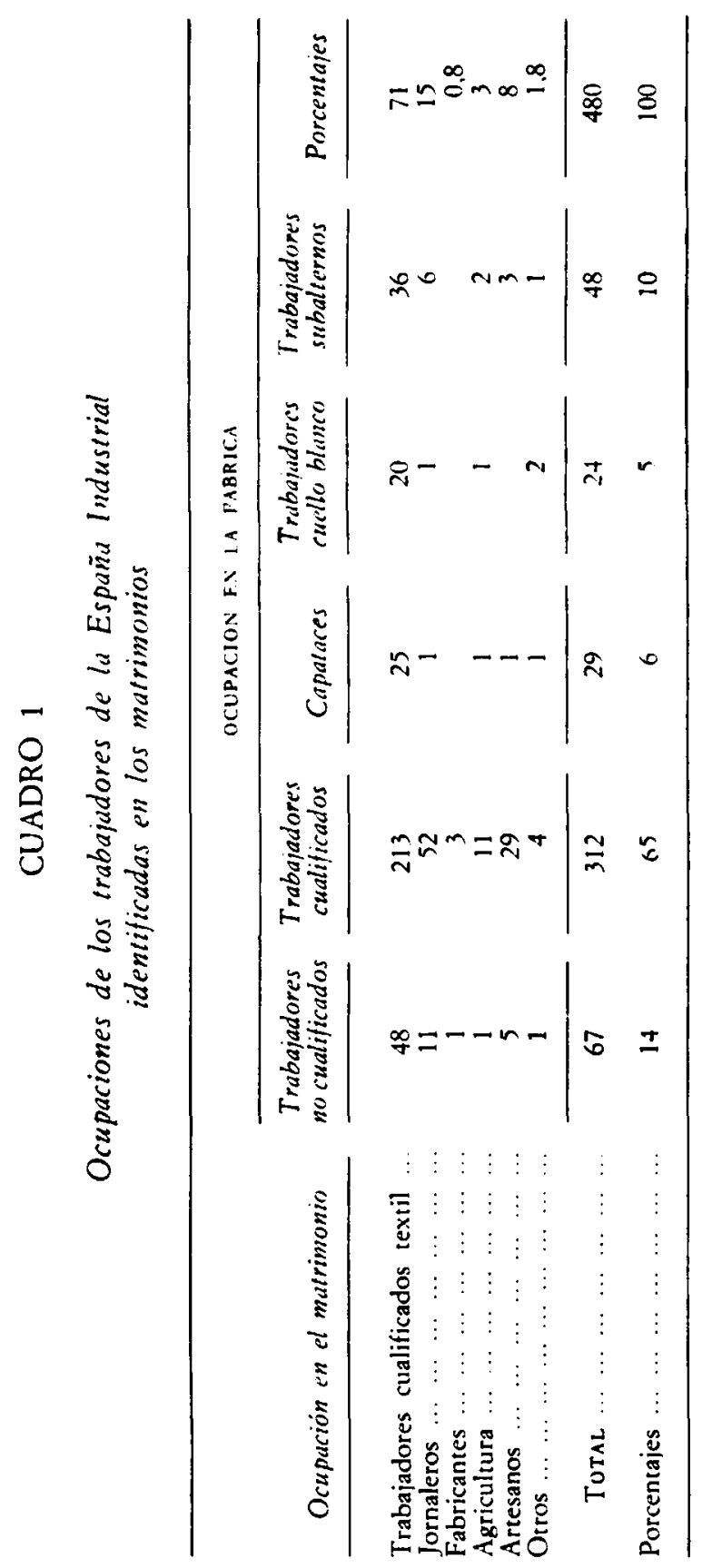




\section{La evolución de la estructura de la ocupación en la España Industrial}

Para analizar las oportunidades salariales que ofrecía la empresa antes se debe estudiar cómo evolucionó la demanda de trabajo en su seno. A partir de tres cortes transversales - 1850,1870 y 1890 - podemos establecer dos grandes periodos en la evolución de la estructura ocupacional de dicha empresa.

Un primer periodo va desde su fundación en 1847 hasta la década de los años 1870. Esta es una fase expansiva, acentuada por la formación de la fábrica de Sants en 1849, que crece a ritmos más acelerados que la fábrica de Barcelona. Durante las décadas de los años 1850 y 1860, la ocupación total que suponían ambas fábricas se multiplicó por tres, pasando de los 273 trabajadores a los 854 , sin contar los tejedores y las hiladoras de selfactinas que trabajaban a destajo. En términos absolutos la ocupación creció para todas las categorías salariales. No obstante, en términos relativos, la ocupación femenina disminuyó. Las mujeres pasan de representar el 52 por 100 de los trabajadores en 1850 al 30 por 100 en 1870 . Ello no se debe a la sustitución de trabajo femenino por trabajo masculino e infantil, sino a la creación de nuevas secciones que requerían de trabajo masculino adulto cualificado. En secciones como la hilatura se observa, no obstante, si tomamos el jornal de 8 reales como el salario mínimo que cobraba un hombre adulto, la sustitución de trabajo masculino adulto por trabajo infantil. Sin embargo, la formación de las secciones antes mencionadas compensa los efectos de dicha sustitución en la jerarquía ocupacional de la fábrica, de forma que la estructura salarial de la empresa permanece relativamente estable, aumentando el porcentaje de trabajadores en la parte media del abanico salarial.

Las secciones de nueva creación son las que requerían de trabajo altamente cualificado y que, en la literatura, se han considerado como la aristocracia obrera - trabajadores de las máquinas a vapor o en todas las tareas de los estampados- y también otras secciones no directamente relacionadas con el textil -albañilería, hojalatería, carpintería, cerrajería-. Cabe destacar que la creación de dichas secciones no siempre dio oportunidades de promoción a los trabajadores locales, ya que, en la sección de estampados, 19 de los 41 trabajadores que cobraban más de 15 reales de jornal eran extranjeros, tal como sus nombres y apellido indican.

Se puede también subrayar que los salarios percibidos por los hombres son muy distintos de los de las mujeres. Así, en 1870, el 82,11 por 100 de los hombres cobraba 8 o más reales, pudiéndose suponer que la proporción restante eran niños, mientras que sólo el 10,43 por 100 de las mujeres cobraba dicha cantidad o más - véase cuadro 2-. Estas diferencias no se deben sólo a exigencias de cualificación. De hecho es paradójico que una trabajadora cualificada, una hiladora en una máquina continua, cobrase salarios muy similares 


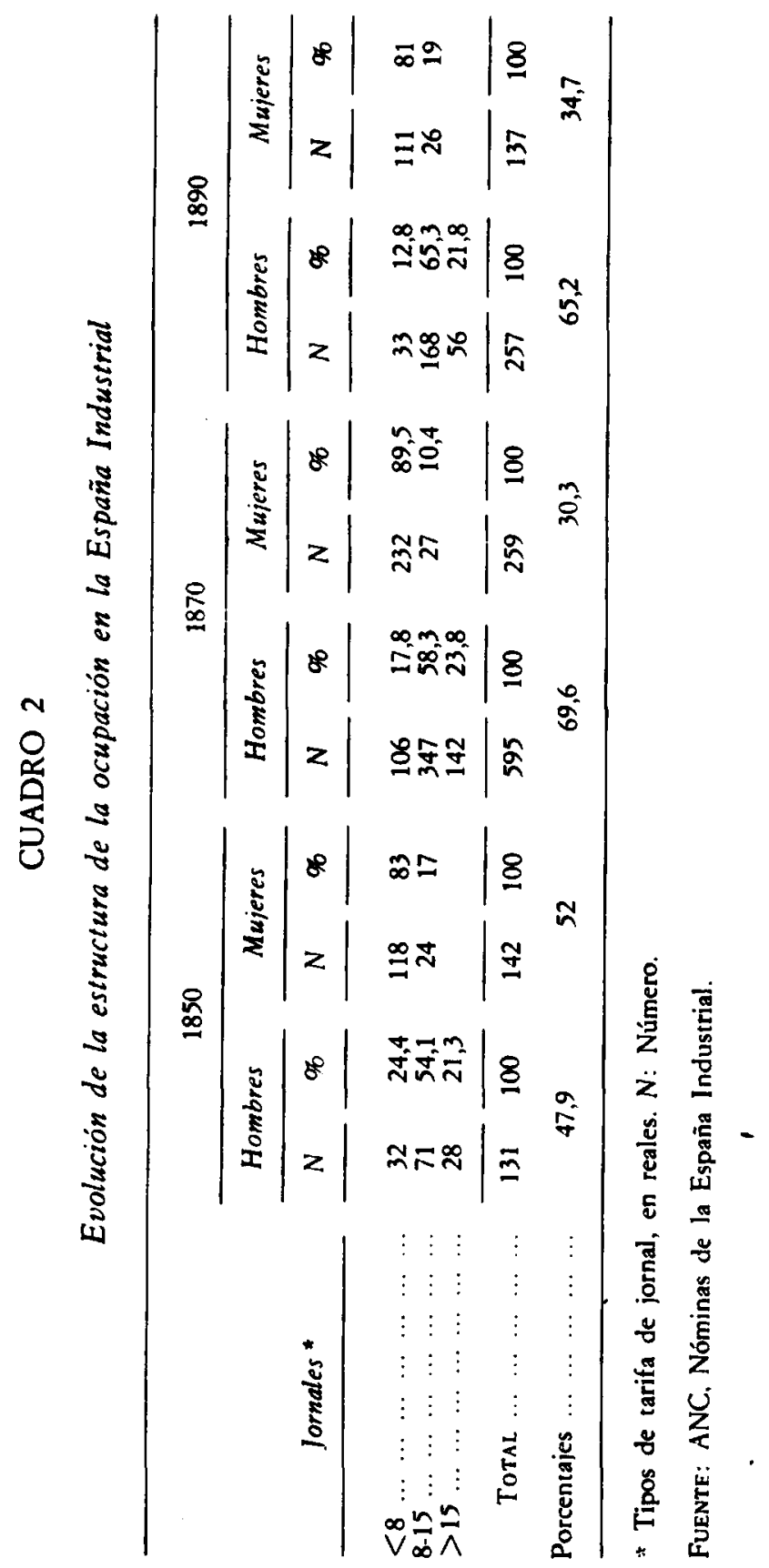


a los de las trabajadoras auxiliares y, en algunos casos, inferiores. En 1870, una hiladora de continua cobraba 7 reales de jornal, mientras que una nudadora de la sección de preparados de tejidos cobraba entre 8 y 9,5 reales. El abanico salarial femenino era muy estrecho y parece estar fijado por la costumbre, más que por criterios de cualificación.

En segundo lugar, se puede observar otro período, durante los años 1870 y 1880 , que podemos considerar recesivo, ya que la empresa reduce la ocupación en un 53 por 100 , pasando de los 854 trabajadores en 1870 a los 394 en 1890, siempre sin contar los tejedores y las hiladoras de selfactinas que continuaban trabajando a destajo. Podemos afirmar que dicha reducción de la ocupación no fue debida a aumentos de la productividad del trabajo en la tejeduría. Tomando una muestra del producto elaborado producido por la fábrica, los tejidos, se puede comprobar cómo éste se reduce en un 47 por 100 entre ambas fechas, proporción idéntica a la disminución de la ocupación en los oficios textiles, si no contamos los 104 trabajadores ocupados en 1870 en secciones como la albañileria. carpinteria y cerrajería, de los que la empresa ya ha prescindido en la segunda fecha ${ }^{1:}$. Estce es, pues, un periodo de recesión. que se agudiza enl los años de 1880 . en que se reduce sensiblemente el output de la empresa y ésta pasa a prescindir de más de la mitad de los rraba. jadores.

Cabe destacar que las tareas centrales del proceso productivo, la tejeduría y la hilatura, siguieron organizadas sobre bases tradicionales durante todo el período. Las 50 hiladoras de selfactinas que aparecen en las nóminas de 1870 habían de descontar de su ingreso bruto los salarios de 150 trabajadoras más. Habían, por tanto, de compatibilizar su trabajo manual con las tareas de supervisión de un número elevado de trabajadoras auxiliares. No hay indicios de que el mantenimiento de dicho sistema de organización del trabajo obedeciese a criterios de productividad. En esta dirección parece plausible la hipótesis de Lazonik de que la excesiva competencia entre empresas impidió racio. nalizar la organización del trabajo, en detrimento de mayores aumentos de la productividad ${ }^{\mathrm{I}}$.

\section{Los mecanismos de asignación del trubajo v el salario. según cobortes de matrimonio}

Para analizar los factores predominantes en la determinación del salario se ha tratado, en primer lugar, de mostrar la influencia de la edad sobre el

"En cambio, hay evidencias del aumento de la productividad del trabajo en la hila

tura, debido a la renovación tecnolúgica de las fábricas en el período $1887-1890$.
ló Las hipótesis en esta dirección de este autor se pueden encontrar en Lazonik (1979). 
ingreso. Así, se ha reconstruido el salario a lo largo del ciclo'vital, de todos los trabajadores reclutados por la empresa en un período expansivo, entre 1847 y 1857. Tal como se ha explicado ya, la disposición de la documentación en el archivo permite sólo reconstruir el ciclo vital masculino, y el enlace de la información de la empresa con la eclesiástica hace reducir sensiblemente la muestra.

En el gráfico 1 y el cuadro 3 se puede observar cómo el salario mèdio de los trabajadores estaba estrechamente correlacionado con la edad, variable que aquí se estima a partir del tiempo respecto del matrimonio. Cada punto del gráfico 1 es la media aritmética de los salarios de los trabajadores que

\section{GRAFICO 1}

Salario masculino a lo largo del ciclo vital

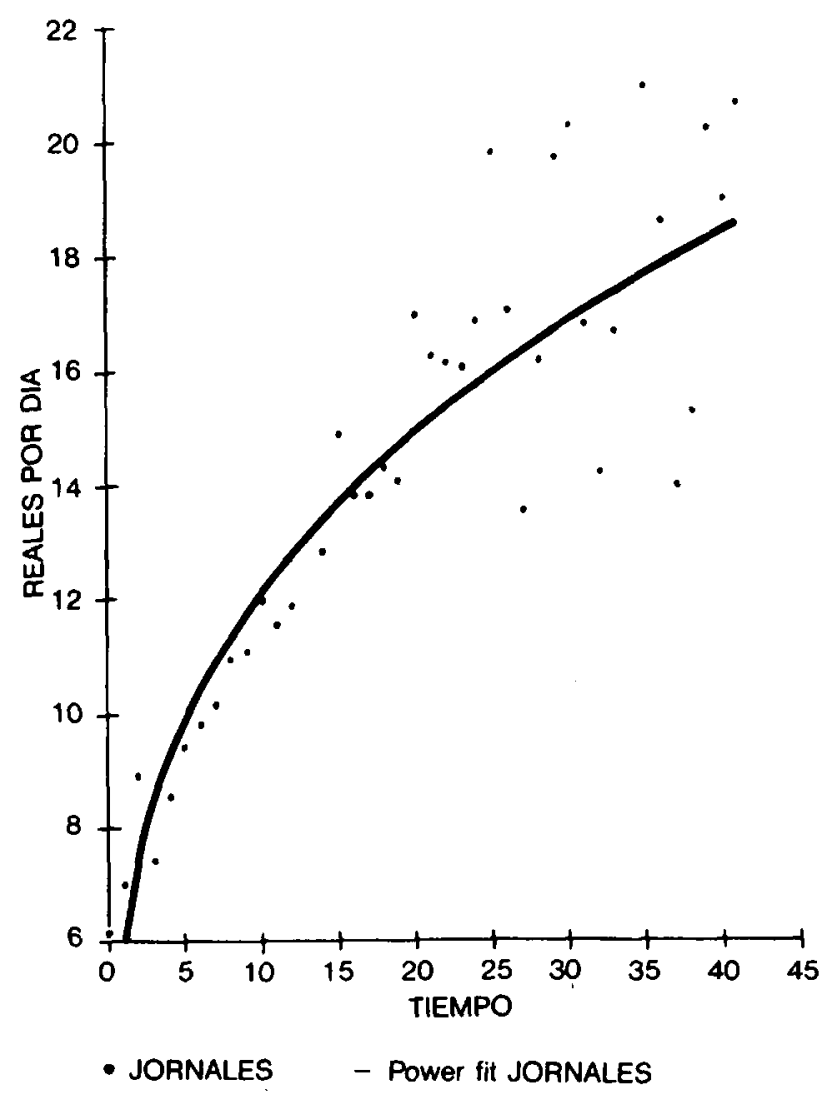




\section{CUADRO 3}

Evolución del jornal medio a lo largo del ciclo vical, 1847-1887

(En reales)

\begin{tabular}{|c|c|c|c|c|c|}
\hline $\begin{array}{l}\text { Tiempo } \\
\text { respecto del } \\
\text { matrimonio } \\
\text { (1) }\end{array}$ & $\begin{array}{c}\text { Número } \\
\text { observa- } \\
\text { ciones } \\
\text { (2) }\end{array}$ & $\begin{array}{l}\text { Jornal } \\
\text { medio } \\
\text { (3) }\end{array}$ & $\begin{array}{l}\text { Tiempo } \\
\text { respecto del } \\
\text { matrimonio } \\
\text { (1) }\end{array}$ & $\begin{array}{c}\text { Número } \\
\text { observa- } \\
\text { ciones } \\
\text { (2) }\end{array}$ & $\begin{array}{l}\text { Jornal } \\
\text { medio } \\
\text { (3) }\end{array}$ \\
\hline $\begin{array}{r}-9 \\
-8 \\
-7 \\
-6 \\
-5 \\
-4 \\
-3 \\
-2 \\
-1 \\
-1 \\
1 \\
2 \\
3 \\
4 \\
5 \\
6 \\
7 \\
8 \\
9 \\
10 \\
11\end{array}$ & $\begin{array}{r}79 \\
50 \\
50 \\
60 \\
66 \\
74 \\
76 \\
80 \\
78 \\
84 \\
104 \\
98 \\
94 \\
83 \\
79 \\
66 \\
74 \\
69 \\
64 \\
75 \\
66\end{array}$ & $\begin{array}{c}6,08 \\
6,92 \\
8,86 \\
7,34 \\
8,5 \\
9,34 \\
9,77 \\
10,09 \\
10,9 \\
11,03 \\
11,91 \\
11,48 \\
11,82 \\
13 \\
12,79 \\
14,83 \\
13,78 \\
13,75 \\
14,27 \\
14 \\
16,94\end{array}$ & $\begin{array}{l}12 \\
13 \\
14 \\
15 \\
16 \\
17 \\
18 \\
19 \\
20 \\
21 \\
22 \\
23 \\
24 \\
25 \\
26 \\
27 \\
28 \\
29 \\
30 \\
31 \\
32\end{array}$ & $\begin{array}{l}56 \\
39 \\
36 \\
33 \\
36 \\
34 \\
16 \\
22 \\
17 \\
24 \\
22 \\
15 \\
20 \\
13 \\
16 \\
19 \\
14 \\
11 \\
12 \\
11 \\
13\end{array}$ & $\begin{array}{l}16,2 \\
16,1 \\
16 \\
16,8 \\
19,7 \\
17 \\
13,5 \\
16,1 \\
19,7 \\
20,24 \\
16,75 \\
14,14 \\
16,6 \\
17,5 \\
20,9 \\
18,6 \\
14 \\
15,3 \\
20,2 \\
18,9 \\
20,6\end{array}$ \\
\hline
\end{tabular}

FUENTE: Elaboración propia.

se hallaban en un determinado momento del ciclo vital. Si $X$ es la variable tiempo en años transcurridos a partir de la edad de quince e $Y$ es la variable salario diario, la especificación de la relación funcional resultante es la siguiente:

$$
Y=a \cdot X^{b}
$$

Aplicando el método de mínimos cuadrados obtenemos los siguientes valores de los coeficientes:

$$
Y=6,0345 \cdot X^{0,3027}
$$


La bondad del ajuste de la función obtenida se verifica al comprobar el valor de los estadísticos correspondientes:

$R^{2}=0,8799 ; R^{2}$ ajust:ido $=0,8769$.

Coeficiente de correlación $=0,88$.

Desviación típica del coeficiente $a=0,0508$.

Desviación típica del coeficiente $b=0,0176$.

Estadístico $T^{2}$ del coeficiente $a=118$.

Estadístico $T^{2}$ del coeficiente $b=17$.

La función resultante es creciente, pero su derivada primera es decreciente -véase gráfico 1-. El salario que cobraban a lo largo de la vida el conjunto de generaciones estudiadas aumentaba siempre con el tiempo, aunque la tasa de incremento disminuyese con la edad. Así, las mayores tasas de aumento se alcanzan a edades muy jóvenes, tendiendo a estabilizarse la evolución del ingreso para edades avanzadas.

Un primer rasgo a destacar es la forma, marcadamente cóncava, de la curva de ingresos a lo largo del ciclo vital. La evolución de los ingresos con la edad de los trabajadores de la España Industrial es, de hecho, sensiblemente distinta a la curva del ciclo vital propuesta por $G$. Becker - véase gráfico 2-. Para este autor, en ausencia de formación de capital humano, los ingresos a lo largo de la vida se podrían representar gráficamente con una recta horizontal, es decir, no aumentarían con la edad -línea $U$ del gráfico 2En cambio, en caso de que hubiese formación de capital humano, la curva de ingresos pasaría de tener una forma convexa en la primera fase, a una forma cóncava, en la segunda - curva $T$ del gráfico 2- La parte convexa correspondería a la fase en que el trabajador, si la formación es general, o el trabajador y la empresa, si es específica, invertirían en capital humano. Los costes de esta inversión harían que el ingreso percibido por el trabajador fuese inferior al salario de los trabajadores sin formación de capital humano. El sacrificio en esta fase se vería no obstante compensado por los ingresos futuros, en el período en que tanto el trabajador como la empresa se beneficiarian de la inversión anterior. En esta fase, los ingresos de los trabajadores serían sensiblemente superiores a los de los que no habían invertido en capital humano y la evolución del salario con la edad pasaría a tener una forma cóncava. La concavidad en esta fase se explica, siguiendo al mismo autor, por la influencia de la edad en la tasa de incremento del ingreso, ya que a edades jóvenes la productividad del trabajo aumenta a un ritmo superior que a edades avanzadas. La curva $T$ del gráfico 2 sería tanto más inclinada cuanto mayor fuese la inversión en capital humano, ya que tanto los costes iniciales 


\section{GRAFICO 2}

Salario a lo largo del ciclo vital, según G. S. Becker

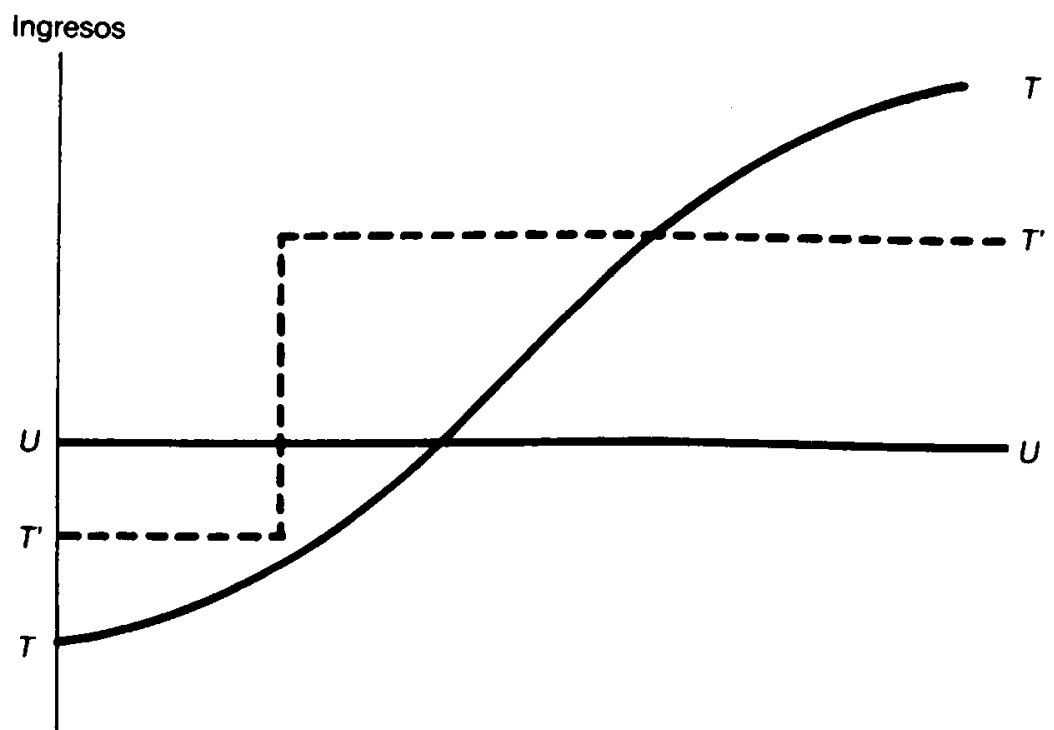

Fuente: G. S. Becker (1983), p. 40.

Edad

como los ingresos futuros aumentarían, y también más cóncava en la segunda fase, por el efecto de la edad sobre el ritmo de crecimiento de la productividad del trabajo ${ }^{17}$.

Tal como se ha observado, nuestros datos empíricos no dan evidencias de un sacrificio inicial en aras de un mayor ingreso futuro a lo largo del ciclo vital. Es en la fase inicial del ciclo vital en la que, según G. Becker, las tasas de crecimiento del ingreso con la edad son bajas debido a que se están pagando los costes de formación. cuando el salario percibido por los trabajadores crece a ritmos superiores, siendo la forma de la curva totalmente cóncava y no convexa. Aunque se constata la influencia de la edad en el ritmo de crecimiento de los salarios, en cambio no hay indicios de inversión en capital humano.

$\mathrm{Si}$ no encontramos evidencias sobre la influencia de la formación de capital humano en la determinación del salario. ¿por qué los salarios eran crecientes a lo largo de la vida?

\footnotetext{
"Becker (1964), p. 15
} 
Tal como se puede observar en el gráfico 3 y el cuadro 4, el salario masculino estaba directamente correlacionado con la antigüedad, sobre todo durante los quince primeros años de estancia en la empresa. El salario masculino medio aumentaba en un 50 por 100 a los diez primeros años de antigüedad y casi se doblaba a los veinte años. Este hecho sugiere la existencia de mercados internos dentro de la empresa. El salario aumentaba con la edad, por las oportunidades de promoción interna que ofrecía la permanencia en la empresa. La tasa de aumento era mayor en los primeros años, hecho que tiende a explicar la concavidad de la curva de ingresos a lo largo de la vida.

\section{GRAFICO 3}

Salarios, según antigüedad y sexo

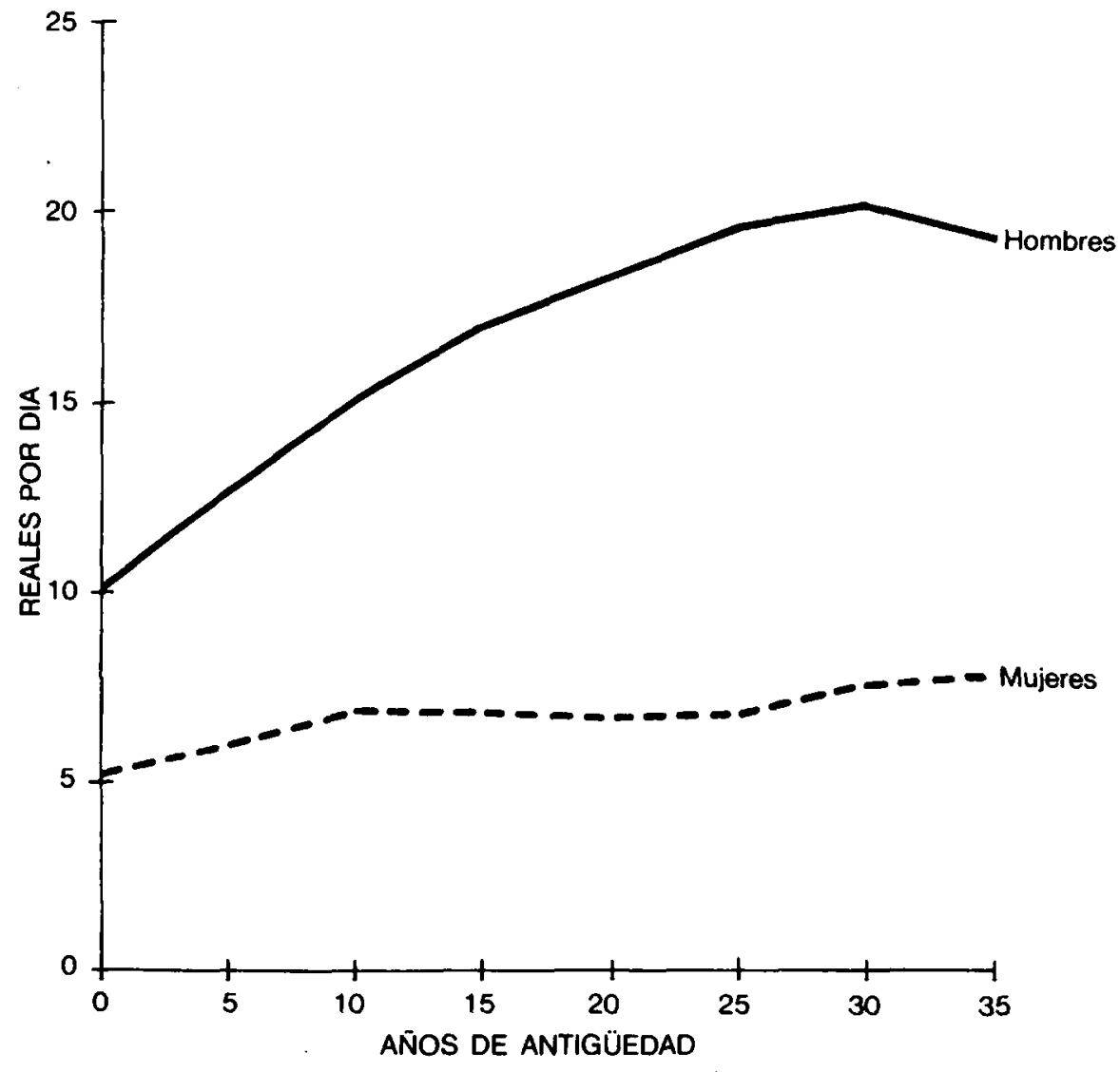




\section{CUADRO 4}

Evolución del jornal medio, según la antigüedad y el sexo

(En reales/día) *

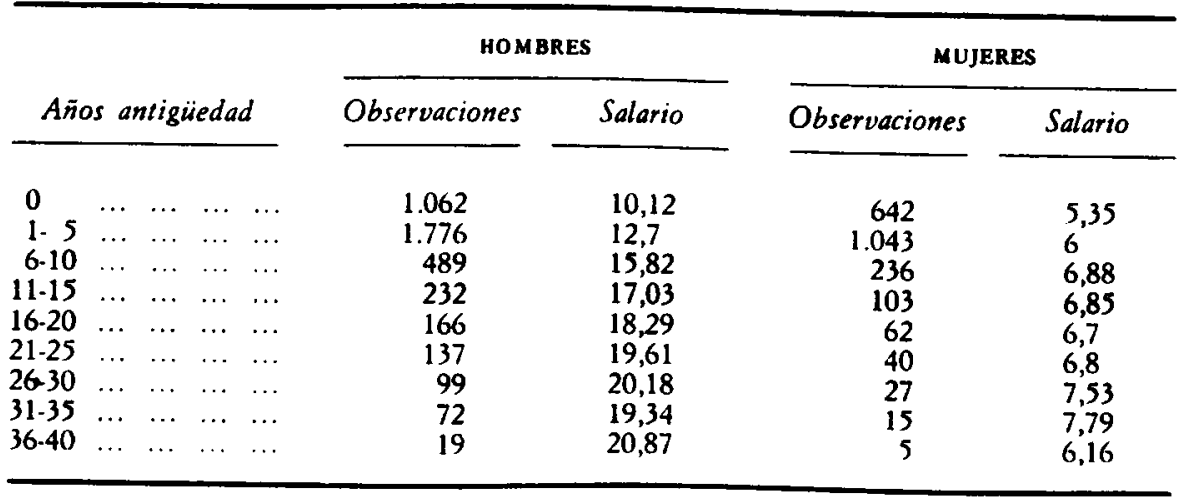

* La fuerte disminución en el número de observaciones a partir de los cinco y diez años de antigüedad se debe, en parte, a los criterios de selección de la muestra, que pasa de observaciones anuales durante los primeros diez años, a observaciones quinquenales en el período siguiente.

Fuente: Nóminas de la España Industrial de 1847 a 1887.

En los mismos, gráfico y cuadro, se puede observar cómo el salario femenino aumenta sólo muy ligeramente con la antigüedad. Las mujeres tenian, pues, muy pocas oportunidades de promoción dentro de la empresa. Adicionalmente al funcionamiento de mercados internos, cerrados a la competencia del mercado abierto, se puede observar la segmentación del mercado de trabajo según el sexo.

Este hecho se podría deber a los límites que la tecnología ofrecía en términos de oportunidades de promoción dentro de la empresa, en el sentido en que argumentan $M$. Brown y P. Philips ${ }^{18}$. Tanto los hombres trabajadores, que querrían limitar la competencia para acceder a los puestos de trabajo mejor retribuidos, como los empresarios, que no estarían interesados en ampliar la comunidad potencial de individuos que querían acceder a determinadas ocupaciones, coincidirian en sus intereses de excluir a las mujeres de las escaleras de promoción interna.

De hecho, se ha subrayado ya que el abanico salarial femenino era muy estrecho y que hay evidencias de que el ingreso de las mujeres estaba fijado

13 Brown y Philips (1986). 
más por criterios consuetudinarios que por pautas de cualificación y de productividad. Más que a factores tecnológicos y de competencia interna, el bajo y estable salario femenino se puede explicar por la herencia de los criterios preindustriales en las pautas que gobernaban la economía familiar. Desde la perspectiva de los hombres trabajadores, el hecho de que se asignase a las mujeres trabajos cualificados y en otros contextos bien pagados ${ }^{19}$, como la hilatura, manteniendo bajos sus salarios, no hacía disminuir la competencia interna, sino que reducía el abanico de ocupaciones cualificadas a las que los propios hombres podían acceder. El hecho que el salario femenino siguiese teniendo un papel de soporte o complemento para la economía familiar fue aprovechado por los empresarios para proveerse de trabajo barato en algunas de las facetas del proceso productivo. A pesar de que el tiempo de permanencia en la empresa de las mujeres fuera menor al de los hombres, la inestabilidad del trabajo femenino se veía compensada, desde el punto de vista de los empresarios, por los bajos salarios y por la reducción de costes de trabajo que éstos suponían.

Al observar las escaleras ocupacionales mediante las cuales los hombres alcanzaban aumentos salariales se puede destacar que el 44 por 100 de los trabajadores que habian alcanzado diez años de antigüedad y el 37,7 por 100 de los que llegan a los veinte años, figuran en la nómina con oficios idénticos a lo largo del tiempo. Este hecho es contradictorio con el sentido que dan Piore y Doeringer a las escaleras ocupacionales, que habían de asegurar incrementos salariales por la promoción de los trabajadores a puestos mejor retribuidos ${ }^{20}$. La consecución de incrementos salariales con una misma ocupación a lo largo del tiempo sugiere, en cambio, la hipótesis de que la función que ejercía el trabajador dentro de la empresa cambiaba con la antiguiedad. Ello indicaría que, al igual que en la hilatura y la tejeduría, los trabajadores estables pasaban a asumir tareas de supervisión y control del proceso productivo, que les daban derecho a salarios superiores a los de los trabajadores recién llegados y que realizaban un oficio u ocupación idéntico. De nuevo, este hecho tendería a reforzar la idea de que la organización del trabajo seguía basada, en la segunda mitad del siglo xix, en criterios tradicionales que permitían, a los trabajadores de un mismo oficio, obtener salarios superiores si permanecían estables en una misma empresa.

Un segundo rasgo a destacar es que una proporción notable de los trabajadores cambiaba de sección con el pasar del tiempo. Un 25 por 100 de los trabajadores con diez años de antigüedad y un 32 por 100 después de veinte años, habían alcanzado, en la gran mayoría de los casos, incrementos salariales,

\footnotetext{
19 Camps (1985).

20 Piore y Doeringer (1983) y (1985).
} 
mediante el cambio de sección. Para una proporción que va desde una cuarta parte a un tercio de los trabajadores estables, los aumentos salariales con la antigüedad no se derivan del capital humano acumulado por la experiencia en el trabajo y el mejor conocimiento de la maquinaria y del equipo productivo, ya que con el pasar del tiempo habían cambiado de sección. Ello sugiere que no sólo los factores relacionados con la experiencia incidían en la asignación del trabajo y la fijación del salario.

De hecho, las escaleras ocupacionales, en el sentido que Doeriger y Piore les atribuyen, se cumplen sólo para un 30 por 100 de los trabajadores que permanecían en la empresa entre diez y veinte años. Para casi un tercio de los trabajadores estables, la antigüedad proporcionaba posibilidades de ascenso dentro de la sección. Cuando este tipo de promoción se llevaba a cabo, era la que garantizaba aumentos salariales más sensibles, ya que el 30 por 100 de los trabajadores que accedían a este tipo de escaleras ocupacionales doblaban o más su salario al cabo de diez años y el 38 por 100 percibían estos incrementos salariales al cabo de veinte años. No obstante, ésta es una proporción minoritaria de los trabajadores estables. Ello sugiere que la influencia de la cualificación en la promoción interna no era el único factor explicativo de los aumentos salariales a lo largo de la vida, en el sentido argumentado por Piore y Doeringer. Aproximadamente, un tercio de los trabajadores cambiaba de sección con la antigüedad y el otro tercio seguía realizando la misma ocupación.

Una segunda hipótesis a contrastar es si el tipo de mecanismos de asignación del trabajo era distinto según el grado de cualificación, es decir, si existía dualidad en el mercado de trabajo, aparte de la segmentación ya observada según el sexo.

En el cuadro 5 y el gráfico 4 se puede observar cómo las escalas salariales eran distintas según la cualificación, aunque las diferencias tendían a disminuir con la antigüedad. Paradójicamente, los trabajadores no cualificados eran los que percibían incrementos salariales más sensibles en los primeros años de antigüedad, llegando a casi doblar sus salarios a los diez años de permanencia en la empresa. Cabe sin embargo destacar que sus salarios, en el momento de entrar en la empresa, eran muy bajos y que sólo una proporción muy minoritaria llegaba a los diez años de antigüedad. De hecho, la permanencia media en la empresa de los trabajadores no cualificados era de tres años, y el grado de rotación del trabajo no cualificado era, por tanto, muy elevado.

Los trabajadores cualificados tenían siempre una posición más favorable en el abanico salarial, aunque su tasa de incremento del salario, según la antigüedad, fuese menor que la de los trabajadores no cualificados. Tenían, asimismo, una posición más estable en la empresa - siete años de perma- 


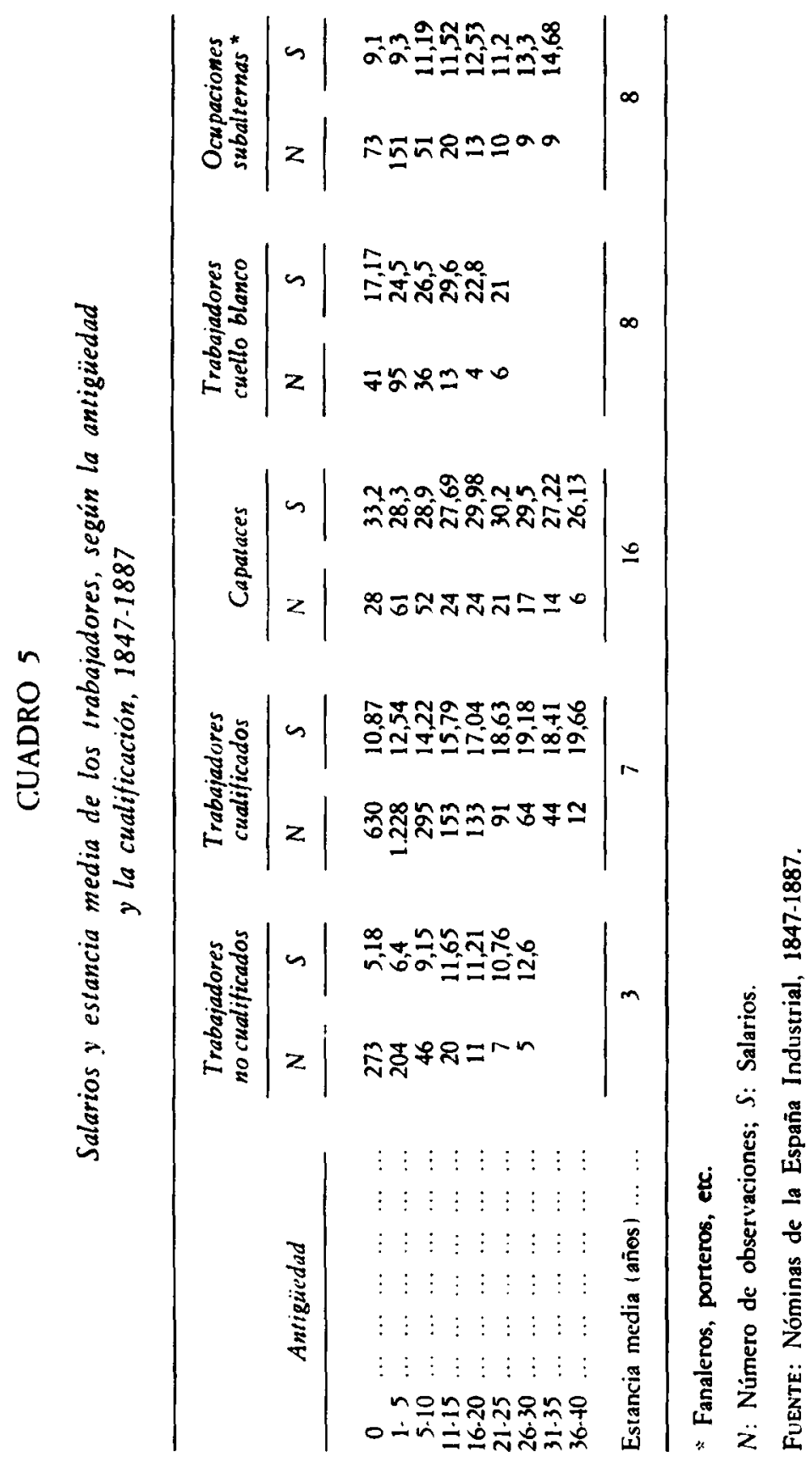




\section{GRAFICO 4}

Salarios, según cualificación

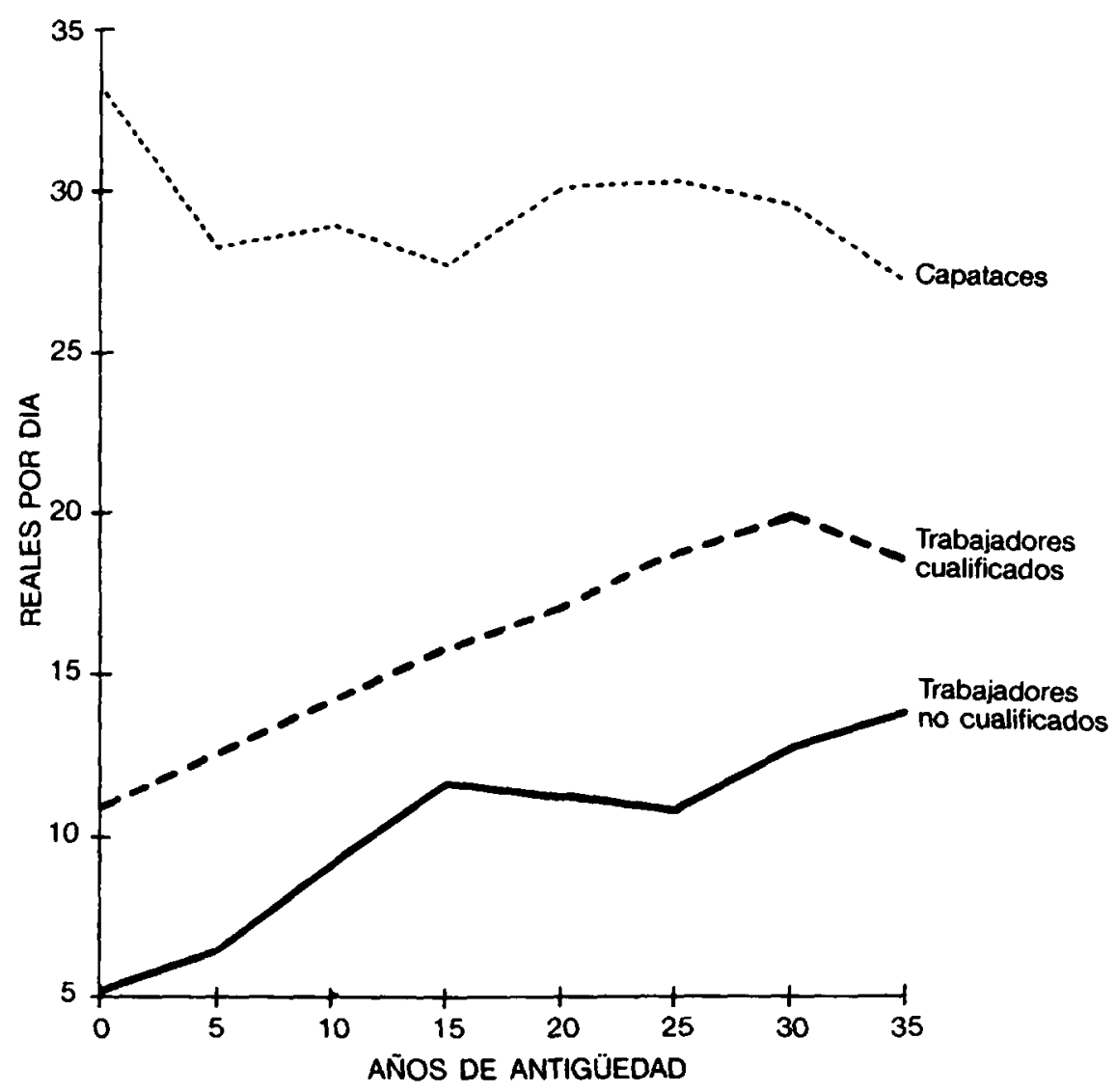

nencia media-, muy parecida a la alcanzada por los trabajadores de cuello blanco que podríamos identificar con la aristocracia obrera.

Las oscilaciones que se observan en el salario percibido por los capataces, según la antigüedad, son debidas a que éstos cobraban según mensualidades y no por jornal trabajado. Se ha calculado su ingreso diario dividiendo por 27 su mensualidad. Sin duda, ésta llevaba incorporada primas y horas extraordinarias, que no se han tenido en cuenta entre los otros tipos de trabajadores, para los que se ha tomado el tipo de jornal. La influencia de los pagos extraordinarios hace variar sensiblemente el cálculo del ingreso diario según la antigüedad. No obstante, se puede observar cómo su ingreso es el 
triple que el de un trabajador cualificado para una antigüedad de menos de un año y no aumenta con el paso del tiempo, de forma que su posición relativa dentro de la empresa tiende a desmejorar con la antigüedad. Asimismo, son los trabajadores que tienen una posición más estable dentro de la empresa, con una permanencia media de dieciséis años.

Tal como se observa en el cuadro 3, las mujeres se sitúan en la situación más desfavorable dentro de la jerarquía ocupacional de la empresa. Sus salarios para una antigüedad de menos de un año son parecidos a los de los trabajadores no cualificados, sólo que no perciben los incrementos salariales alcanzados por los segundos con la antigüedad. Su posición en la empresa es sólo ligeramente más estable que la de los trabajadores no cualificados, con cinco años de estancia media.

El comportamiento de los salarios y la permanenca media, según la cualificación, nos podría llevar a dos tipos de hipótesis. En primer lugar, los incrementos salariales, según la antigüedad, eran tanto más agudos cuanto menos favorable era la posición inicial del trabajador en la empresa, exceptuando el caso de las mujeres. Este hecho contradice la literatura sobre la sindicación en el siglo xIx, que muestra que sólo los trabajadores cualificados estaban sindicados y eran, por tanto, los que percibían incrementos salariales superiores ${ }^{21}$. En nuestro caso, en cambio, los trabajadores no cualificados son los que perciben incrementos salariales más sensibles, sólo comparables con los de los trabajadores de cuello blanco que, sin duda, no estaban sindicados.

En segundo lugar, el abanico salarial y la estancia media en la empresa, según la cualificación, abren la hipótesis de una posible segmentación del mercado de trabajo. Así, los trabajadores no cualificados, los peor pagados, son los más inestables y tendrían, por tanto, pocas expectativas de promoción en la empresa. La estancia media máxima es la que se observa entre los capataces, los trabajadores mejor pagados en todos los niveles de antigüedad, que eran los seleccionados por la empresa para controlar la producción.

Cuando se relaciona el comportamiento del mercado de trabajo según la cualificación, con el ciclo vital, ambos tipos de hipótesis se desvanecen. Tal como muestra el cuadro 6, el hecho de ser trabajador no cualificado no era un atributo permanente a lo largo de la vida. Los trabajadores no cualificados se concentran en una fase del ciclo vital que va desde los diez años antes del matrimonio a las primeras nupcias. Aunque la presencia de los trabajadores cualificados antes del matrimonio es notable, su número tiende a aumentar después del matrimonio. La cualificación era, pues, un proceso a lo largo de la vida, de manera que la formación se llevaba a cabo en la

\footnotetext{
"Hobsbawm (1964), cap. 15.
} 


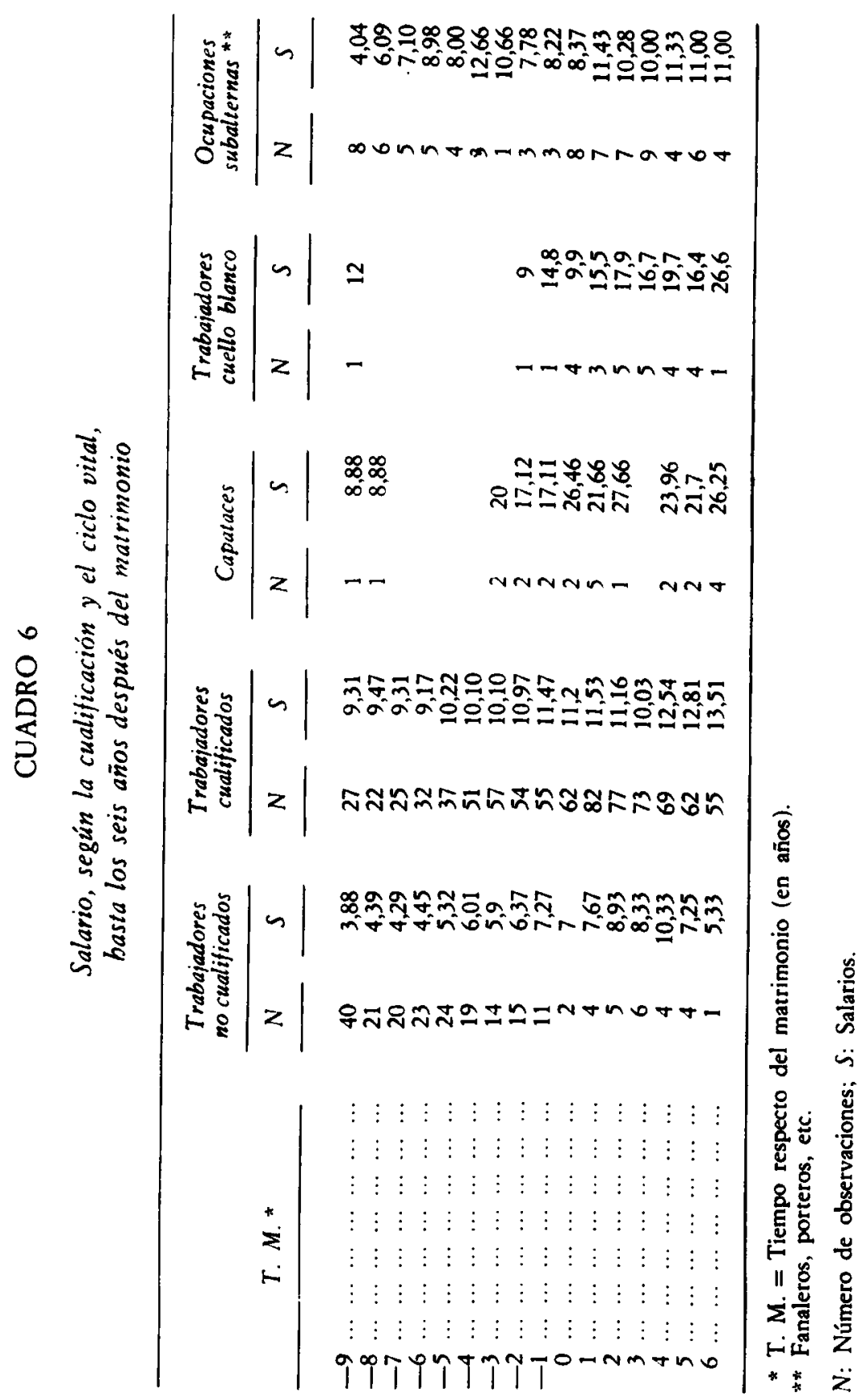


juventud, antes del matrimonio, mientras que a partir de las primeras nupcias casi todos los trabajadores eran ya cualificados.

La muestra para las otras categorías ocupacionales es demasiado pequeña para sacar algún tipo de conclusión, pero las observaciones disponibles para los capataces y los trabajadores de cuello blanco se sitúan también después del matrimonio. Lo que a primera vista se podría considerar un comportamiento segmentado del mercado de trabajo, obedece, de hecho, a la evolución del proceso de cualificación a lo largo del ciclo vital. Los mayores incrementos salariales observados entre los trabajadores no cualificados se pueden atribuir al hecho que esta categoría ocupacional se sitúa en un período de la vida de formación y también al resultado empírico de que, a edades jóvenes, el ritmo de incremento del salario con la edad es superior. Su situación inestable en el mercado de trabajo se puede considerar asimismo transitoria, ya que al alcanzar mayor grado de cualificación, después del matrimonio, se sitúan en una posición más estable dentro de la empresa.

Así, los datos disponibles muestran que la formación y la cualificación eran un proceso inestable que se llevaba a cabo en la juventud. Este hecho empírico contradice de nuevo las hipótesis de G. Becker ${ }^{22}$ sobre la formación específica. Según el autor, cuando la empresa invierte en la formación de sus empleados tiende a disminuir la rotación del trabajo y aumenta el grado de permanencia del trabajador en la empresa. Paradójicamente, en nuestro caso, el período de formación, para el que se observan incrementos salariales mayores con la edad, es el período más inestable de la vida de un trabajador y con mayor rotación del trabajo entre empresas. Los mayores grados de permanencia en la empresa se observan no entre los trabajadores no cualificados, en los cuales la empresa hipotéticamente invertiría, sino entre los trabajadores que entran en la empresa ya como trabajadores cualificados. El hecho de que el proceso de cualificación fuera inestable sugiere, asimismo, que las prácticas del trabajo, ya avanzada la revolución industrial, se parecían a las prácticas tradicionales en que el aprendiz era muy móvil y trabajaba para varios maestros antes de alcanzar una posición estable.

De la combinación de los factores hasta aquí expuestos, resulta la experiencia laboral de las cohortes de trabajadores escogidas en la muestra. Dadas las características de la muestra de trabajadores escogida, todos los que la fábrica reclutó en sus diez primeros años de existencia y la metodología utilizada para la identificación. de los trabajadores en los expedientes matrimoniales, sólo podemos estudiar las cohortes o promociones de matrimonios que celebraron las primeras nupcias entre 1837 y 1867 . Estas cohortes se han

"G. Becker (1983) y (1985). 


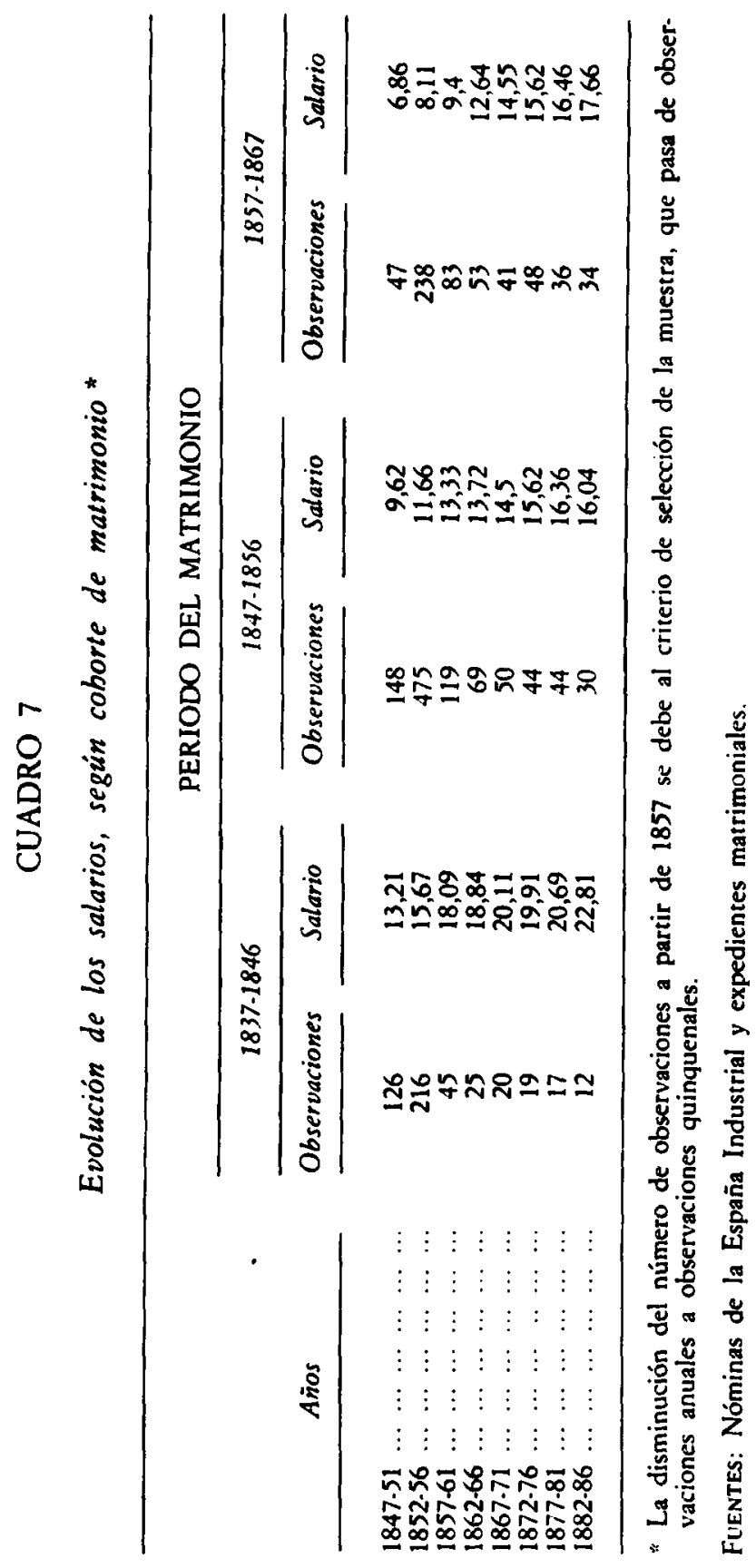


agrupado en tres promociones de matrimonios que celebraron el esposorio en intervalos de diez años.

Tal como se puede observar en el gráfico 5 y el cuadro 7, los salarios nominales entre 1847 y 1887 son crecientes para todas las cohortes de matrimonio. No obstante, la experiencia de cada generación es distinta. Mientras que hasta 1857 las segunda y tercera cohortes podrán en su momento optar a los salarios recibidos por la primera a las mismas edades (suponiendo edades similares de matrimonio), a partir de esta fecha los trabajadores de la primera promoción pasan a recibir salarios que nunca alcanzarán las cohortes sucesivas.

\section{GRAFICO 5}

Salarios, según la cohorte de matrimonio

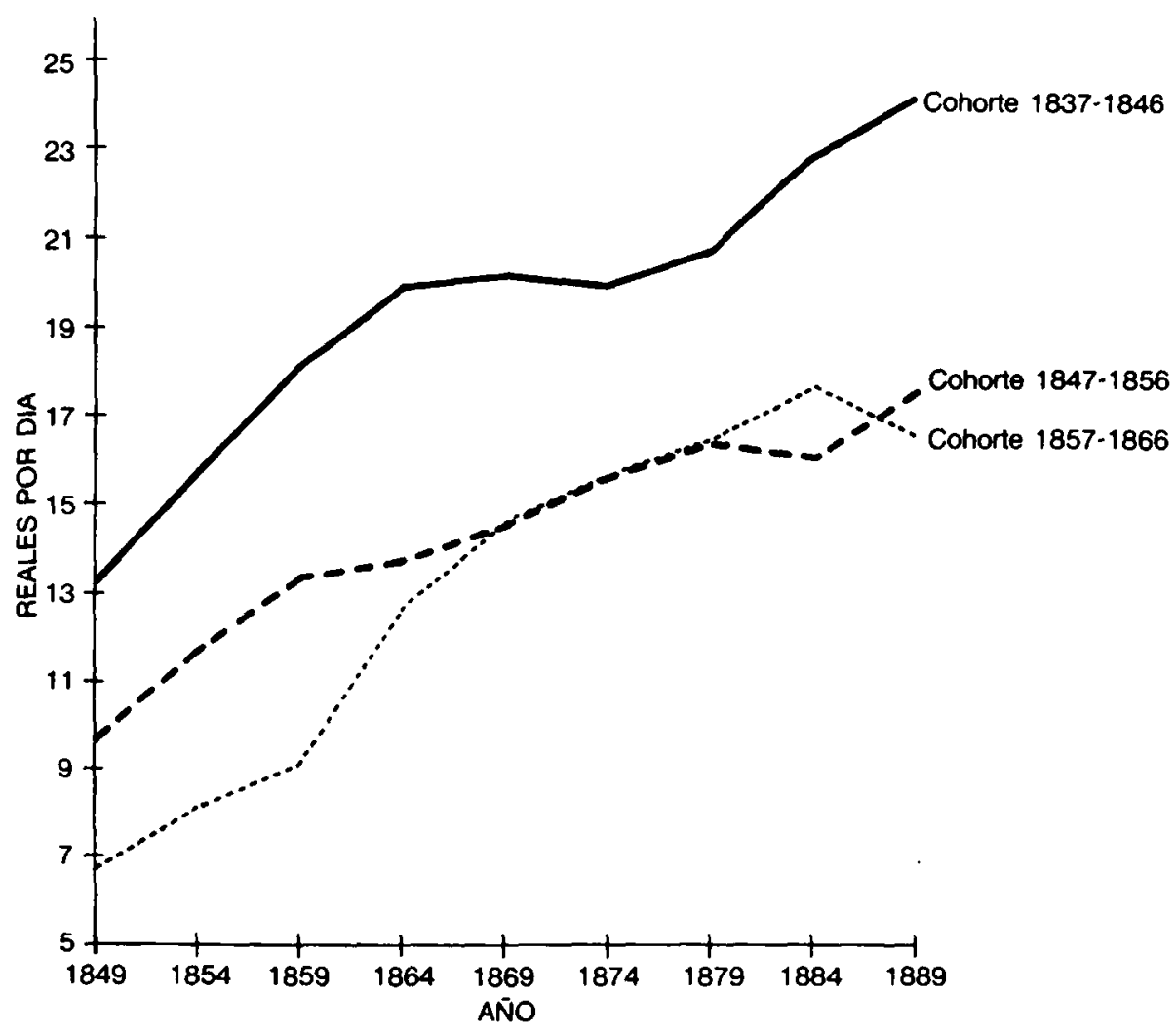


En la fecha mencionada, y dadas las oportunidades de ascenso social que ofrecía la empresa, la primera promoción pasa a saturar la demanda del trabajo mejor retribuido de la empresa (capataces y trabajadores de la administración). Los efectos de la mortalidad de los trabajadores de la primera cohorte sobre la creación de vacantes en los puestos de trabajo mejor retribuidos no había de dar a los trabajadores de las promociones sucesivas oportunidades similares a las que, por término medio, ofreció la empresa a los primeros trabajadores adultos que llegaron en la fase de su creación y expansión. En este período, la demanda del trabajo mejor pagado creció, lógicamente, a ritmos más acelerados de los que la mortalidad de los trabajadores de la primera promoción había de propiciar a partir de 1857 .

Se puede también observar cómo, a partir del quinquenio 1867-1871, al final de la fase expansiva de la empresa los trabajadores de la tercera promoción alcanzan a los de la segunda. Ello indica que, a edades más jóvenes, los trabajadores de la tercera cohorte obtuvieron los mismos salarios que los de la segunda. Este tipo de comportamiento se mantiene a lo largo del período recesivo, en las décadas de 1870 y 1880 . Así, pues, en todo el período en que se reduce la ocupación de la empresa en términos absolutos, ésta pasa a basarse más en el reclutamiento interno de los trabajadores cualificados en la parte media del abanico salarial, promocionando a los trabajadores más jóvenes que entraron entre 1847 y 1857 . Esta promoción interna tenía sin embargo unos límites que son los alcanzados por la segunda cohorte de matrimonios. Es de suponer que la experiencia de las promociones de matrimonios sucesivas a las estudiadas fuese peor, ya que, al igual que la primera cohorte saturó los puestos de trabajo altos en el abanico salarial, la segunda y tercera promociones coparan las ocupaciones de la parte media, en un contexto en que el empleo se reducía en más de la mitad.

Dadas las características del ciclo vital y de las escaleras ocupacionales de la empresa, el momento histórico y la edad en que un trabajador entró en la fábrica, era decisivo en la evolución de su ingreso futuro. La experiencia de las tres cohortes estudiadas es bien diversa y muestra cómo la mejor estrategia de un trabajador adulto ya cualificado era entrar en una empresa de nueva creación, que era la que le daba más oportunidades de promoción
interna.

Se ha mostrado cómo el funcionamiento del mercado de trabajo en el caso catalán pone de relieve las oportunidades de promoción de los trabajadores dentro de la empresa, de modo que éstos tenían un salario creciente a lo largo del ciclo vital. Las evidencias empíricas encontradas muestran, asimismo, el escaso poder explicativo del modelo neoclásico de la formación de capital humano. Ni la evolución del salario a lo largo del ciclo vital, ni las 
formas de aprendizaje, se ajustan a las características del modelo de capital humano tal como lo especifica $G$. Becker.

Aunque de forma informal y no siempre con las características especificadas por Doeriger y Piore, podemos hablar del funcionamiento de mercados internos en una gran empresa, en el contexto catalán de la segunda mitad del siglo xix. Este hallazgo es importante, ya que muestra que el surgimiento de mercados internos es el resultado de la transición al sistema fabril y no de las modernas formas de gestión y negociación entre empresa y trabajadores del siglo xx. No obstante, ¿a qué obedece su aparición en el siglo xix?

Las explicaciones sobre el surgimiento de los mercados internos varían mucho, según los autores. Para algunos son el resultado del proceso de cualificación dentro de la empresa ${ }^{23}$, aunque dicho proceso tenga características distintas a las avanzadas por el modelo de formación de capital humano. Para otros, obedecen a una estrategia de los empresarios para dividir la clase trabajadora, al crear una estructura jerarquizada ${ }^{24}$. Un tercer tipo de explicación pone énfasis en las presiones de la clase trabajadora para limitar la arbitrariedad de los capitalistas, imponiendo el ctiterio de la antigüedad, válido para todos los trabajadores, en las promociones dentro de la em. presa ${ }^{25}$.

En el contexto catalán, la literautra sobre el movimiento obrero no pone de relieve la reivindicación de las promociones internas e incrementos salariales según la antigüedad por parte de los trabajadores ${ }^{2 h}$. Se ha mostrado también cómo la promoción interna dentro de la empresa obedecía sólo en una tercera parte de los casos a criterios de cualificación y cómo el proceso de apren. dizaje era muy inestable, requiriendo de la rotación del trabajo entre em. presas. Por último, dadas las características de la organización del trabajo dentro de la empresa, los mercados internos parecen más el resultado de una adaptación de las pautas tradicionales de organización del trabajo al sistema fabril, que una estrategia de los empresarios para dividir a la clase trabajadora. A lo largo del siglo xix, tanto la tejeduria como la hilatura seguian organizadas sobre bases tradicionales. Se ha mostrado también cómo alrededor del 40 por 100 de los trabajadores que alcanzaron incrementos salariales con la antigüedad seguían realizando oficios idénticos y cómo este

"Doeringer y Piore (1983) y (1985).

* Gordon, Edwards y Reich (1986).

"S Jacoby (1984).

26 Izard (1973), Termes (1972), Maluquer de Motes (1977) y Gabriel (1980). A pesar de que la literatura no recoja esta información, la prensa obrera da, en cambio, evidencias de la preferencia de los trabajadores por mantener el criterio de la antigüedad en los nue. vos contratos. Asi, en Barcelona, en 1892, los trabajadores reivindican que «... en caso de necesitarse más personal, den, según cosiumbre, los fabricantes, preferencia a los operarios antiguos, y en caso contrario, despidan a los más modernos", en Nuevo Régimen, Ma. drid, 18 de junio de 1892. Agradezco esta información a Antonio López Estudillo. 
hecho sugiere que su función dentro de la empresa se modificaba a lo largo del tiempo, pasando a realizar tareas de supervisión, compatibles con el trabajo manual. La estructura interna de la empresa seguía jerarquizada y las oportunidades de acceder a los puestos relativamente mejor retribuidos dependían de la antigüedad, factor éste estrechamente relacionado con el ciclo vital.

Con todo ello no se quiere sugerir que la transición al sistema fabril no significase una ruptura en las pautas de organización del trabajo. Sin duda, era muy distinto trabajar en la España Industrial a hacerlo en un taller artesano. Se quiere sólo mostrar que esta transición no se hizo en el vacío y que muchas de las prácticas del trabajo tradicionales seguían vigentes a finales del siglo xix. Ello hace que los modelos más extendidos sobre el mercado de trabajo no se adapten, o se adapten sólo en parte, a la realidad de la fábrica estudiada. En esta dirección, las evidencias presentadas por E. P. Thompson para la primera mitad del siglo $x ı x$, de predominio de las prácticas artesanales en Inglaterra, parecen tener cierta vigencia en el contexto fabril de la Cataluña de la segunda mitad del siglo xix ${ }^{27}$. Ello es relevante porque muestra que ya desde la transición al sistema fabril, el mercado abierto, de libre competencia, no operaba. La adecuación de los empresarios a las formas tradicionales de organización del trabajo había de resultar en los primeros mercados internos, aún informales, que daban mecanismos de control del trabajo, así como sistemas de cualificación y reclutamiento interno de los trabajadores. En ellos hay que buscar los origenes de los modernos mercados internos del siglo $\mathbf{x x}$.

\footnotetext{
17 Thompson (1966).
} 


\section{BIBLIOGRAFIA}

Becker, G. S. (1964): Human Capital. A Theoretical and Empirical Analysis with Special Reference to Education. Nueva York.

- (1983): «Inversión en capitul humano e ingresos», en L. Toharia, El mercado de tra. bajo: teorias y aplicaciones, Madrid.

Brown, M., y PHILIPS, P. (1986): «The historical origin of job ladders in U. S. canning industry and their effects on gender division of labours, Cambridge Journal of Economics, núm. 10, pp. 129.145.

CAMPS, E. (1985): La formació d'una ciutat catalana sola l'impuls de la industrialització, tesis de grado inédita, Bellaterra.

- (1990): Migraciones internas y formación del mercado de trabajo en la Cataluña industrial en el siglo XIX, tesis doctoral inédita, Instituto Universitario Europeo, Florencia.

Doeringer. P. B., y Piore, M. J. (1983): «Los mercados internos de trabajo», en L. Toharin, El mercado de trabajo: teorias y aplicaciones, Madrid.

- (1985): Mercados internos de trabajo y análisis laboral. Madrid.

GABRIEL, P. (1980): Classe obrera $i$ sindicats a Catalunya, 1903-1920, tesis doctoral inédita, Bellaterra.

Gordon, D. M.; Edwards, R., y Reich, M. (1986): Trabajo segmentado, trabajadores divididos. La translormación bistórica del trabajo en Estados Unidos, Madrid.

Hoвsвawm, E. J. (1964): Labouring Men. Studies in the History of Labour, Londres.

IZARD, M. (1973): Industrialización y obrerismo, Barcelona.

JАСOBY, S. M. (1984): «The Development of Internal Labor Markets in American Manufacturing Firmsw, en P. Osternan, Internal Labour Markets, Cambridge.

LAZONIK, W. (1979): «Industrial relations and technical change: the case of the self-acting mulew, Cambridge Journal of Economics, núm. 3, pp. 231-262.

MaluQuer de Motes, J. (1977): El socialismo en España, Barcelona.

Osterman, P. (1984): «Introduction: the Nature and Importance of Internal Labour Markets , en P. Osterman, Internal Labour Markets, Cambridge.

Piore, M. J. (1983): «Notas para una teoría de la estratificación del mercado de trabajom, en L. Toharia, El mercado de trabajo: teorias y aplicaciones, Madrid.

Sxolnick, M., y otros (1977): "Conference on Methods of Automatic Family Reconstitution», IUSSP Papers, Florencia.

Sundstrom, W. A. (1988): «Internal Labor Markets before World War I. On-the-Job Training and Employee Promotions, Explorations in Economic History, núm. 25

Termes, J. (1972): Anarquismo y sindicalismo en España. La Primera Internacional, 1864-1881, Barcelona.

Tном PSON, E. P. (1966): The Making of the English Working Class, Londres.

Williamson, J. G. (1987): Capitalismo y desigualdad en Gran Bretaña, Madrid.

Winchester, E. A., y SChofield, R. S. (1973): "Nominal record linkage by computer and the logic of family reconstitutionsw, en E. A. WRIGLEY, Identijying People in the Past, Londres. 